\title{
Update: Interim Guidance for the Evaluation and Management of Infants with Possible Congenital Zika Virus Infection — United States, August 2016
}

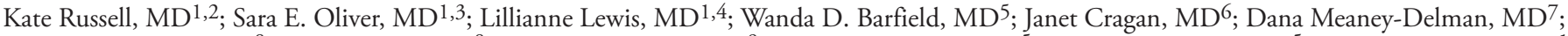 \\ J. Erin Staples, MD, PhD ${ }^{8}$; Marc Fischer, MD ${ }^{8}$; Georgina Peacock, MD ; Titilope Oduyebo, MD ${ }^{5}$; Emily E. Petersen, MD ${ }^{5}$; Sherif Zaki, MD, PhD ${ }^{10}$; \\ Cynthia A. Moore, $\mathrm{MD}, \mathrm{PhD}^{6}$; Sonja A. Rasmussen, $\mathrm{MD}^{11}$; Contributors
}

On August 19, 2016, this report was posted as an MMWR Early Release on the MMWR website (http://www.cdc.gov/mmwr).

CDC has updated its interim guidance for U.S. health care providers caring for infants born to mothers with possible Zika virus infection during pregnancy (1). Laboratory testing is recommended for 1 ) infants born to mothers with laboratory evidence of Zika virus infection during pregnancy and 2) infants who have abnormal clinical or neuroimaging findings suggestive of congenital Zika syndrome and a maternal epidemiologic link suggesting possible transmission, regardless of maternal Zika virus test results. Congenital Zika syndrome is a recently recognized pattern of congenital anomalies associated with Zika virus infection during pregnancy that includes microcephaly, intracranial calcifications or other brain anomalies, or eye anomalies, among others (2). Recommended infant laboratory evaluation includes both molecular (real-time reverse transcription-polymerase chain reaction [rRT-PCR]) and serologic (immunoglobulin $\mathrm{M}[\operatorname{IgM}])$ testing. Initial samples should be collected directly from the infant in the first 2 days of life, if possible; testing of cord blood is not recommended. A positive infant serum or urine rRT-PCR test result confirms congenital Zika virus infection. Positive Zika virus IgM testing, with a negative rRTPCR result, indicates probable congenital Zika virus infection. In addition to infant $Z$ ika virus testing, initial evaluation of all infants born to mothers with laboratory evidence of Zika virus infection during pregnancy should include a comprehensive physical examination, including a neurologic examination, postnatal head ultrasound, and standard newborn hearing screen. Infants with laboratory evidence of congenital Zika virus infection should have a comprehensive ophthalmologic exam and hearing assessment by auditory brainstem response (ABR) testing before 1 month of age. Recommendations for follow-up of infants with laboratory evidence of congenital Zika virus infection depend on whether abnormalities consistent with congenital Zika syndrome are present. Infants with abnormalities consistent with congenital Zika syndrome should have a coordinated evaluation by multiple specialists within the first month of life; additional evaluations will be needed within the first year of life, including assessments of vision, hearing, feeding, growth, and neurodevelopmental and endocrine function. Families and caregivers will also need ongoing psychosocial support and assistance with coordination of care. Infants with laboratory evidence of congenital Zika virus infection without apparent abnormalities should have ongoing developmental monitoring and screening by the primary care provider; repeat hearing testing is recommended. This guidance will be updated when additional information becomes available.

Zika virus infection during pregnancy is a cause of microcephaly and other serious brain anomalies (3); however, the clinical spectrum of the effects of Zika virus infection during pregnancy is not yet known. A wide range of neurologic abnormalities, in addition to microcephaly, has been observed among infants with presumed or confirmed congenital Zika virus infection $(2,4)$. Reported neuroimaging findings include intracranial calcifications; ventriculomegaly and extra-axial fluid; abnormal gyral patterns (e.g., polymicrogyria); decreased brain parenchymal volume; cortical atrophy and malformation; hypoplasia of the cerebellum, cerebellar vermis or brainstem; delayed myelination; and thinning or hypoplasia of the corpus callosum $(5,6)$. Neurologic abnormalities apparent on examination of these infants have included hypertonia, hypotonia, spasticity, hyperreflexia, severe irritability, and seizures $(2,4)$. Zika virus appears to primarily target neural progenitor cells resulting in cell death and disruption of neuronal proliferation, migration and differentiation, which slows brain growth and affects neural cell viability (7-9). Ocular findings reported in infants with presumed or confirmed congenital Zika virus infection have included chorioretinal atrophy or scarring, pigmentary changes, optic nerve hypoplasia, optic disc pallor, increased optic disc cupping, hemorrhagic retinopathy and abnormal retinal vasculature $(10-12)$. Some infants with presumed or confirmed congenital Zika virus infection have had a phenotype consistent with fetal brain disruption sequence, characterized by severe microcephaly, collapse of the skull, overlapping cranial sutures, prominent occipital bone, redundant scalp skin, and severe neurologic impairment $(13,14)$. Other findings seen in infants with congenital Zika virus infection have included clubfoot and contractures of single or multiple joints (arthrogryposis), presumably secondary to central nervous system damage (4).

Experience with other congenital infections can provide insight to guide clinical management until more data emerge 
regarding outcomes associated with congenital Zika virus infection. Infants with congenital infections, such as cytomegalovirus (CMV) and rubella, can develop a range of clinical manifestations, including hearing loss, seizures, neurodevelopmental delays and diabetes mellitus later in life $(15,16)$, even without apparent clinical manifestations of congenital infection at birth (17).

Diagnostic testing for congenital Zika virus infection can be challenging. Whereas a positive molecular (rRT-PCR) testing result in an infant can confirm Zika virus infection, a negative result does not exclude infection. Viral shedding can be prolonged in congenital CMV and rubella infections $(18,19)$; however, little is known about the duration of viral shedding in infants with congenital Zika virus infection. IgM results might assist in making the diagnosis, but can be difficult to interpret because of false-positive results occurring from cross-reacting IgM antibodies or nonspecific reactivity (20). Because maternal IgG crosses the placenta, the presence of $\operatorname{IgG}$ in an infant specimen cannot be used as evidence of congenital infection.

Currently, there are $>1,000$ pregnant women with laboratory evidence of possible Zika virus infection in the United States and U.S. territories (http://www.cdc.gov/zika/geo/ pregwomen-uscases.html). Pediatric health care providers need information to guide appropriate laboratory testing and clinical evaluation and management of infants born to these mothers. On July 21-22, 2016, CDC, in collaboration with the American Academy of Pediatrics (AAP), convened a meeting to obtain individual input from experts and partners to inform the development of guidance for the evaluation and management of infants with congenital Zika virus infection. In attendance were experts in pediatrics, infectious diseases, neurology, developmental and behavioral pediatrics, ophthalmology, audiology, physical medicine and rehabilitation, neonatology, lactation and nutrition, maternal-fetal medicine, clinical genetics, hospitalist medicine, neonatology, and endocrinology, and representatives from principal partner groups (Box 1). Discussion focused on three areas: 1) initial evaluation and laboratory testing of infants born to mothers with laboratory evidence of Zika virus infection during pregnancy, 2) outpatient management and follow-up of infants with microcephaly or other findings consistent with congenital Zika syndrome, and 3) outpatient management and follow-up of infants with laboratory evidence of congenital Zika virus infection but without findings consistent with congenital Zika syndrome.

This guidance aims to assist health care providers in the evaluation and management of infants with congenital Zika virus infection based on currently available data on congenital infections with Zika virus and other pathogens. As more information becomes available, this guidance will be updated.

\section{Updated Recommendations for the Initial Laboratory Testing and Evaluation of Infants with Possible Congenital Zika Virus Infection \\ Infant diagnostic testing. Laboratory testing for congenital} Zika virus infection is recommended for infants born to mothers with laboratory evidence of Zika virus infection, and for infants with findings suggestive of congenital Zika syndrome and a maternal epidemiologic link suggesting possible transmission, regardless of maternal testing results (Figure). Laboratory evidence of maternal Zika virus infection includes Zika virus RNA detected in any maternal clinical specimen by rRT-PCR and positive Zika virus IgM with confirmatory neutralizing antibody titer for Zika virus or flavivirus, not otherwise specified. Zika virus rRT-PCR testing should be performed on both infant serum and urine, and Zika virus IgM enzyme-linked immunosorbent assay (ELISA) should concurrently be performed on infant serum. If cerebrospinal fluid (CSF) is obtained for other studies, rRT-PCR testing for Zika virus RNA and Zika virus IgM should be performed on CSF. Laboratory testing should be performed on infant specimens; cord blood is not recommended because it can yield false positive results through contamination with maternal blood and might also yield false negative results (21). Infant laboratory testing for Zika virus should be performed within the first 2 days after birth; if testing is performed later, distinguishing between congenital, perinatal, and postnatal infection will be difficult. If the timing of infection cannot be determined, infants should be managed as if they have congenital Zika virus infection.

A Zika rRT-PCR positive result in an infant sample confirms the diagnosis of congenital Zika virus infection (Table 1). Zika virus IgM detected in an infant, without detectable Zika virus RNA, should be interpreted as probable congenital Zika virus infection. The plaque reduction neutralization test (PRNT) measures virus-specific neutralizing antibodies and is used to confirm the specificity of the IgM antibodies against Zika virus and rule out a false positive IgM result (20). If the infant's initial sample is IgM-positive, but PRNT was not performed on the mother's sample, PRNT should be performed on the infant's initial sample. However, PRNT cannot distinguish between maternal and infant antibodies. Because of this, it might be necessary to wait until the child is at least age 18 months, when maternal antibodies are expected to wane, to confirm congenital infection. PRNT should be performed on a sample collected from a child aged $\geq 18$ months whose initial sample was IgM positive if Zika-specific neutralizing antibodies were detected by PRNT on either the infant's or mother's sample. If the infant's initial sample is negative by both IgM ELISA and rRT-PCR but clinical concerns remain (e.g., microcephaly with negative evaluation for other known causes), PRNT at age 
BOX 1. Areas of expertise and organizations represented at the Clinical Evaluation and Management of Infants with Congenital Zika Virus Infection meeting - Atlanta, Georgia, July 21-22, 2016

\author{
Specialties represented \\ Audiology \\ Clinical genetics \\ Critical care \\ Developmental and behavioral pediatrics \\ Endocrinology \\ Hospitalist medicine \\ Infectious disease \\ Lactation and infant feeding \\ Maternal-fetal medicine \\ Neonatology \\ Neurology \\ Nutrition \\ Ophthalmology \\ Orthopedics \\ Pediatrics \\ Physical medicine and rehabilitation
}

\section{Partner organizations}

American Academy of Family Physicians

American Academy of Pediatrics (including representation

from the Puerto Rico chapter)

American College of Obstetricians and Gynecologists

Association of Maternal \& Child Health Programs

Family Voices, Inc.

March of Dimes

National Association of Pediatric Nurse Practitioners

Parent to Parent of Georgia

Society for Maternal-Fetal Medicine

\section{Federal agencies}

Administration for Children and Families

CDC

Centers for Medicare \& Medicaid Services

Maternal and Child Health Bureau, Health Resources and Services Administration

National Institute of Child Health and Human

Development, National Institutes of Health

Office of the Assistant Secretary for Preparedness and

Response

18 months can be considered. If PRNT results at 18 months are negative, the child is considered to not have congenital Zika virus infection. If PRNT results are positive, congenital Zika infection is presumed, but postnatal infection cannot be excluded, especially for children living in an area with active Zika virus transmission.
In many cases, infant laboratory testing results will not be available before hospital discharge. In these cases, infants should be presumed to have congenital Zika virus infection until test results are available. For the purposes of this guidance, infants with confirmed or probable Zika virus infection should be managed in the same manner.

Detection of Zika virus RNA in the placenta can confirm the presence of maternal infection, but cannot distinguish between maternal and congenital infection. For circumstances in which maternal testing was not previously performed, performed more than 12 weeks after exposure (22), or was not definitive (e.g., flavivirus not otherwise specified) (20), a positive placental rRT-PCR result can confirm maternal Zika virus infection. Based on unpublished CDC data, placentas from mothers with Zika virus infection during pregnancy can have detectable Zika virus RNA at the time of delivery, regardless of the timing of maternal infection. Clinical implications for an infant with Zika virus RNA detected in the placenta, in the absence of laboratory evidence of Zika virus in the infant, are unknown.

Limited data are currently available regarding perinatal Zika virus transmission (23). Guidelines for evaluation and management of infants and children with postnatally acquired Zika virus disease (1) will be updated as more information is available.

Clinical evaluation of infants. Infants born to mothers with laboratory evidence of Zika virus infection should receive a comprehensive physical examination, including precise measurement of head (occipitofrontal) circumference, ${ }^{*}$ length and weight, assessment of gestational age, and examination for neurologic abnormalities and dysmorphic features (Table 2). A postnatal head ultrasound should be performed on all infants born to mothers with laboratory evidence of Zika virus infection before discharge from the hospital, including those infants with normal prenatal ultrasound findings, because some abnormal findings associated with congenital Zika syndrome might not be readily apparent on prenatal ultrasounds. All infants should receive a hearing screen per universal screening recommendations before hospital discharge. Infants with laboratory evidence of congenital Zika virus infection should be referred for a comprehensive ophthalmologic exam and evaluation of hearing by ABR testing before 1 month of age. Other evaluations should be performed as clinically indicated.

Infants with negative IgM and negative rRT-PCR testing born to a mother with laboratory evidence of Zika virus

\footnotetext{
* Standard head circumference charts are based on measurements taken within 24 hours of birth. Additional information on child growth standards is available at http://www.who.int/childgrowth/en/. Additional information on head circumference measurement is available at https://www.cdc.gov/zika/pdfs/ microcephaly_measuring.pdf.
} 
FIGURE. Recommended Zika virus testing and evaluation of infants born to mothers with laboratory evidence of Zika virus infection during pregnancy *

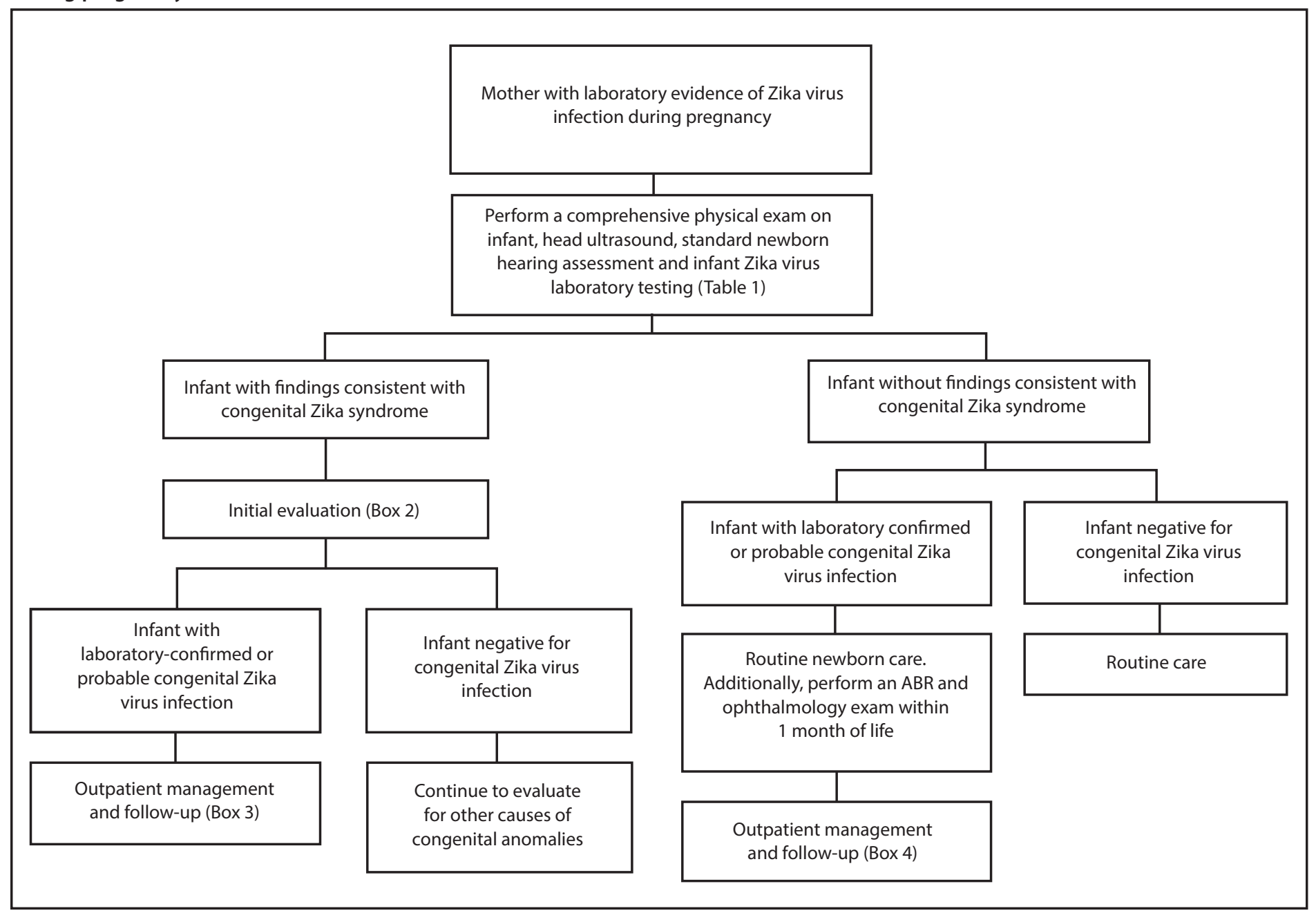

Abbreviation: $A B R=$ auditory brainstem response.

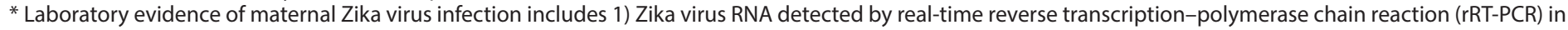

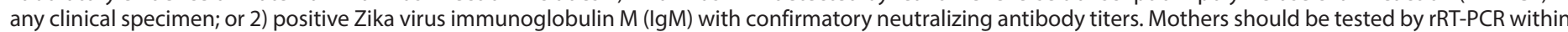

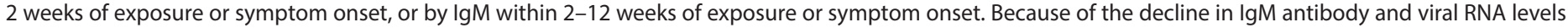

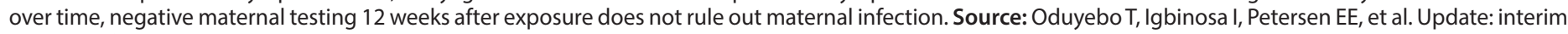

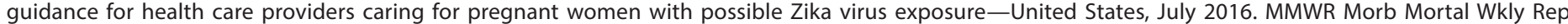
2016;65:739-44. http://dx.doi.org/10.15585/mmwr.mm6529e1.

TABLE 1. Interpretation of results of laboratory testing of infant's blood, urine and/or cerebrospinal fluid for evidence of congenital Zika virus infection

\begin{tabular}{lll}
\hline Infant test results* & \\
\hline rRT-PCR & \multicolumn{1}{c}{$\operatorname{lgM}$} & \multicolumn{1}{c}{ Interpretation } \\
\hline Positive & Positive or Negative & Confirmed congenital Zika virus infection \\
Negative & Positive & Probable congenital Zika virus infection \\
Negative & Negative & Negative for congenital Zika virus infection
\end{tabular}

Abbreviations: $r$ RT-PCR = real-time reverse transcription-polymerase chain reaction; $\lg M=$ immunoglobulin $M$.

* Infant serum, urine, or cerebrospinal fluid.

${ }^{\dagger}$ Laboratory results should be interpreted in the context of timing of infection during pregnancy, maternal serology results, clinical findings consistent with congenital Zika syndrome, and any confirmatory testing with plaque reduction neutralization testing (PRNT). infection should receive routine care, including monitoring of head circumference at every well child visit and age-appropriate developmental screening (24). Health care providers should report information on pregnant women in the United States and the U.S. territories with laboratory evidence of Zika virus infection and their infants (regardless of infant test results) to state, tribal, local, or territorial health departments for inclusion in the U.S. Zika Pregnancy Registry (http://www.cdc. gov/zika/hc-providers/registry.html), or the Puerto Rico Zika Active Pregnancy Surveillance System (ZAPSS) (http://www. cdc.gov/zika/public-health-partners/zapss.html).

For all infants with abnormal findings consistent with congenital Zika syndrome, an extensive evaluation is recommended 
TABLE 2. Initial evaluation and recommended outpatient management during the first 12 months of life for infants with possible congenital Zika virus infection, based on maternal and infant laboratory tests and infant clinical findings

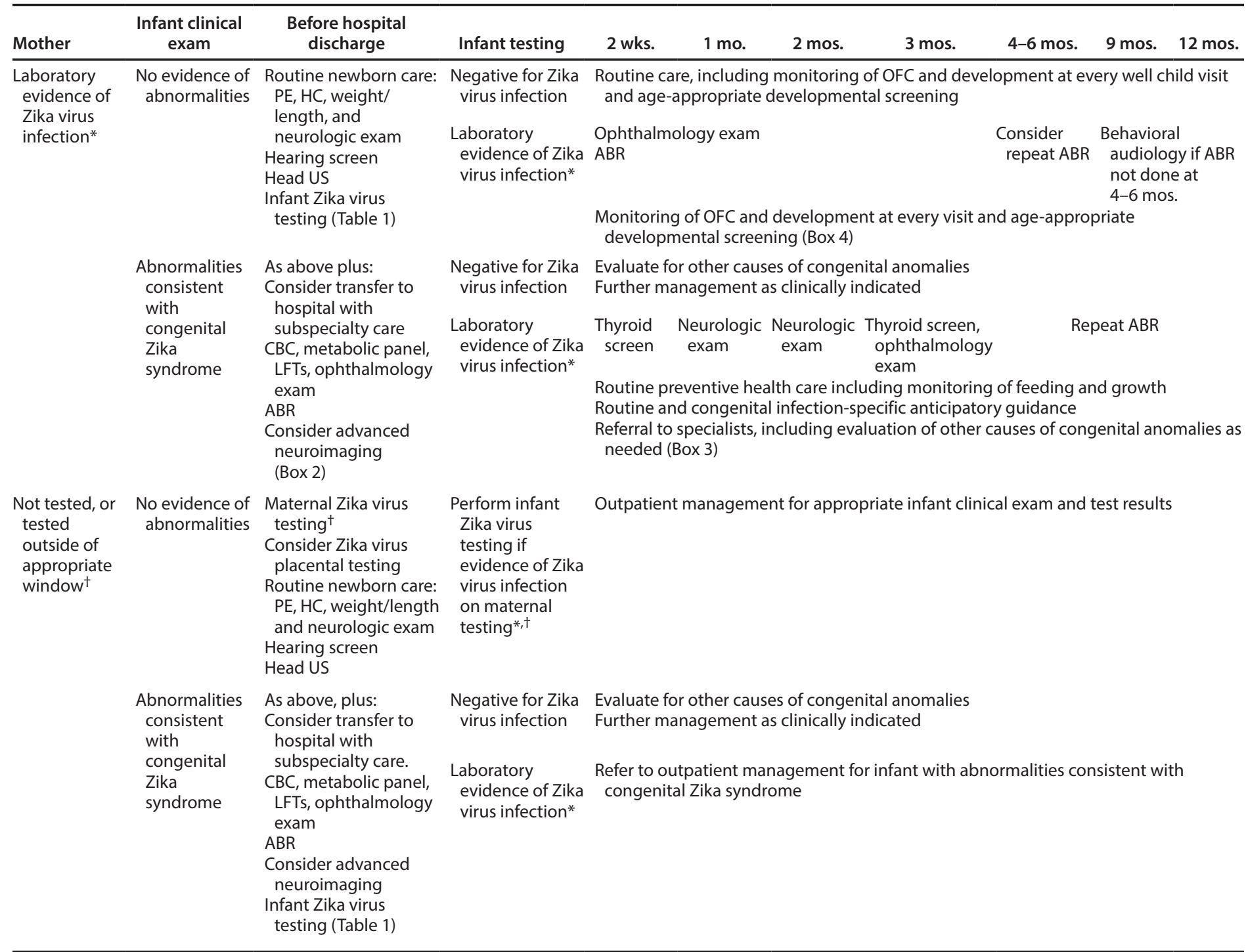

Abbreviations: $\mathrm{ABR}=$ auditory brainstem response; $\mathrm{CBC}=$ complete blood count; $\mathrm{LFTs}=$ liver function tests; $\mathrm{HC}=$ head (occipitofrontal) circumference; $\mathrm{PE}=$ physical examination; rRT-PCR = real-time reverse transcription-polymerase chain reaction; US = ultrasound.

* Laboratory evidence of maternal Zika virus infection includes 1) Zika virus RNA detected by real-time reverse transcription-polymerase chain reaction (rRT-PCR) in any clinical specimen; or 2) positive Zika virus immunoglobulin M ( $\lg M)$ with confirmatory neutralizing antibody titers. Confirmatory neutralizing antibody titers are needed in addition to IgM for maternal Zika virus infection.

${ }^{\dagger}$ Mothers should be tested by rRT-PCR within 2 weeks of exposure or symptom onset, or by lgM within 2-12 weeks of exposure or symptom onset. Because of the decline in IgM antibody titers and viral RNA levels over time, negative maternal testing 12 weeks after exposure does not rule out maternal infection. Source: Oduyebo T, Igbinosa I, Petersen EE, et al. Update: interim guidance for health care providers caring for pregnant women with possible Zika virus exposure-United States, July 2016. MMWR Morb Mortal Wkly Rep 2016;65:739-44. http://dx.doi.org/10.15585/mmwr.mm6529e1. Mothers should be tested by rRT-PCR within 2 weeks of exposure or symptom onset, or by IgM within 2-12 weeks of exposure or symptom onset. Because of the decline in IgM antibody titers and viral RNA levels over time, negative maternal testing 12 weeks after exposure does not rule out maternal infection. http://dx.doi.org/10.15585/mmwr.mm6529e1.

(Box 2). Transfer to a facility with access to pediatric subspecialty care might facilitate this evaluation. However, the decision should not be based solely on the presence of maternal Zika virus infection during pregnancy. Health care providers should consider both the immediate needs of the infant and the potential negative impact of possible separation from his or her family. The recommended evaluation includes a complete blood count and metabolic panel, including liver function tests, a comprehensive examination by an ophthalmologist, ABR testing, and consideration of advanced neuroimaging in consultation with a neurologist. In addition, infants should be evaluated for other causes of microcephaly or intracranial calcifications, including genetic conditions and other congenital infections. 
Infants born to mothers with risk factors for maternal Zika virus infection (travel to or residence in an area of Zika virus transmission or sex with a partner who traveled to or resided in such an area) and for whom maternal testing was not performed before delivery, should have a comprehensive physical examination, including standardized measurement of head circumference. Maternal diagnostic testing should be performed $(20,22)$, and testing of the placenta for Zika virus PCR should be considered (http://www.cdc.gov/zika/hcproviders/test-specimens-at-time-of-birth.html); infant testing should be performed if maternal testing is consistent with laboratory evidence of Zika virus infection. If an infant appears clinically well, further evaluation, including head ultrasound, ophthalmologic assessment, and infant laboratory Zika virus testing, can be deferred until maternal test results are available. However, if there is concern about infant follow-up, head

BOX 2. Initial clinical evaluation and management of infants with laboratory evidence of Zika virus infection and abnormalities consistent with congenital Zika syndrome

- Consultation with:

- Neurologist for determination of appropriate neuroimaging and additional evaluation.

- Infectious disease specialist for diagnostic evaluation of other congenital infections (e.g., syphilis, toxoplasmosis, rubella, cytomegalovirus infection, lymphocytic choriomeningitis virus infection, and herpes simplex virus infection).

- Ophthalmologist for comprehensive eye exam and evaluation for possible cortical visual impairment prior to discharge from the hospital or within 1 month of birth.

- Endocrinologist for evaluation for hypothalamic or pituitary dysfunction.

- Clinical geneticist to evaluate for other causes of microcephaly or other anomalies if present.

- Consider consultation with:

- Orthopedist, physiatrist, or physical therapist for the management of hypertonia, club foot or arthrogrypotic-like conditions.

- Pulmonologist or otolaryngologist for concerns about aspiration.

- Lactation specialist, nutritionist, gastroenterologist, or speech or occupational therapist for the management of feeding issues.

- Perform auditory brainstem response to assess hearing.

- Perform complete blood count and metabolic panel, including liver function tests.

- Provide family and supportive services. ultrasound, ophthalmologic assessment and infant Zika virus testing should be performed before hospital discharge. CDC recommends standard precautions in all health care settings to protect both health care personnel and patients from infection with blood-borne pathogens, including Zika virus (25).

Although Zika virus has been detected in breast milk (26), no cases of Zika virus infection associated with breastfeeding have been reported, and current evidence suggests that the benefits of breastfeeding outweigh the theoretical risks of Zika virus transmission. All women with Zika virus infection during pregnancy should be encouraged and supported to breastfeed their infants, regardless of infant Zika virus testing results.

\section{Outpatient Management of Infants with Laboratory Evidence of Zika Virus Infection and Abnormalities Consistent with Congenital Zika Syndrome}

The care of infants with abnormalities consistent with congenital Zika syndrome requires a multidisciplinary team and an established medical home to facilitate the coordination of care, which is critical to ensuring that these infants receive necessary testing and consultations (Box 3), and that abnormal findings are detected and appropriately addressed (27). If abnormalities are noted on prenatal evaluation, counseling specific to congenital Zika syndrome should occur during pregnancy, preferably with the involvement of obstetric and pediatric providers. Before the infant's discharge from the birth hospital, follow-up appointments with specialists and services recommended during initial evaluation should be made. Consideration should be given to using preexisting coordinated multidisciplinary care clinics.

Infants should receive routine preventive pediatric health care, including regularly scheduled immunizations (24). Families of infants with congenital Zika syndrome should receive information that includes discussion of concerns for development, function, feeding and growth, and prognosis. Standardized measurement of growth parameters, including head circumference, weight, and length, should occur regularly through the first year of life.

Breastfeeding should be encouraged and supported for nutrition and enhanced bonding. Primary care providers should assess the infant for evidence of feeding difficulties and refer for consultations related to lactation, occupational therapy, speech therapy, nutrition, and/or gastroenterology for poor suck, swallowing dysfunction, gastroesophageal reflux, and aspiration. Swallowing dysfunction might not be evident initially and feeding should be monitored closely.

A neurologic examination should be performed at age 1 month and 2 months by a primary care provider and subsequently as 
BOX 3. Outpatient management of infants with laboratory evidence of Zika virus infection and abnormalities consistent with congenital Zika syndrome

- A medical home should be established, and visits with primary care provider should occur monthly for at least the first 6 months of life.

- Follow growth parameters; monitor development; provide routine immunizations, anticipatory guidance, and psychosocial support; and ensure infants receive necessary testing and consultations.

- Neurologic examination by the primary care provider at 1 and 2 months of age. Refer to neurology for any abnormalities, or for any parental or provider concerns.

- Refer to developmental specialist and early intervention services.

- Repeat comprehensive ophthalmologic exam at age 3 months, and refer to ophthalmology for any abnormal findings, or for any parental or provider concerns.

- Repeat auditory brainstem response testing at age 4-6 months, and refer to audiology for any abnormal findings, or for any parental or provider concerns.

- Repeat testing for hypothyroidism at age 2 weeks and age 3 months, even if the initial testing results were normal. Refer to endocrinology for any abnormal findings.

- Provide family and supportive services.

needed depending on the infant's clinical status. If not already initiated, neurology referral should occur for evaluation of any abnormalities, including sleep problems and excess irritability. If the ophthalmology exam performed within the first month of life was normal, another exam (including retinal assessment) is recommended at age 3 months. ABR testing is the preferred test to detect hearing loss resulting from neurologic damage. If the initial newborn hearing screen was performed using only otoacoustic emission testing, the infant should be referred for ABR screening before 1 month of age. If the newborn hearing screen was normal, an ABR should be performed at age 4-6 months. If vision or hearing results are abnormal, referrals to appropriate specialists should occur as soon as possible.

Infants with abnormal brain development can be at risk for hypothalamic dysfunction leading to pituitary insufficiency, and early manifestations of endocrine dysfunction might not be detected by routine newborn screening (28). Thyroid screening, including measurement of thyroid stimulation hormone (TSH) and thyroxine (either free T4 or both total T4 and estimated free T4) should be performed at age 2 weeks and again at age 3 months. If either of these results is abnormal, further evaluation of pituitary function should be performed by an endocrinologist.

Developmental monitoring should occur at each routine visit, and standardized, validated screening tools should be used to assess the presence of developmental delay (24). Referral to a developmental specialist and early intervention services should occur as soon as possible. It is important that primary care providers continue to monitor the child's development and progress with standardized, validated developmental screening tools to ensure that the child's developmental needs are addressed.

Overall, families and caregivers of infants with congenital Zika syndrome will require ongoing psychosocial assessment and support. Health care providers should work closely with parents to ensure that the care plan that is developed is consistent with the infant's needs and the family's wishes. Monitoring for depression among caregivers should occur during primary care visits, because depression or family stress might be associated with the infant's complex medical needs. Families might also face financial stressors, social stigma, and other forms of discrimination. Existing national and local resources for families of children with complex care needs should be made available to families (29).

Referrals for abnormal findings should occur as clinically indicated, either to a pediatric specialist or a specialist with expertise in the care of children. In areas with limited access to pediatric subspecialty care, the numerous services recommended for infants with congenital Zika syndrome might not be readily available; in these situations, telehealth might be explored as a potential means of providing subspecialty care and support to families in areas with limited access (30).

\section{Outpatient Management of Infants with Laboratory Evidence of Zika Virus Infection but Without Abnormalities Consistent with Congenital Zika Syndrome}

Infants with laboratory evidence of Zika virus infection but without apparent abnormalities at birth are recommended to have additional monitoring (Box 4), until further information is available regarding outcomes, because some neurologic sequelae of congenital Zika virus infection (e.g., seizures, cognitive impairment, and vision and hearing abnormalities) might be subtle or have delayed onset. During routine infant follow-up with primary care providers, a standardized, validated developmental screening tool should be used at age 9 months, as currently recommended by the American Academy of Pediatrics (24), or sooner, if there are any developmental concerns. Referral to a developmental specialist and early intervention programs should be considered as soon as caregiver or provider concerns are noted, and additional referrals to specialists should be made as clinically indicated. 
A vision screening, including assessment of visual regard, should be performed at each well child visit, and referral to an ophthalmologist should be made for any caregiver or provider concerns. Infants with abnormalities on initial hearing screen should be referred to an audiologist for a complete evaluation. Later development of hearing loss in infants without other clinical findings has been observed in other congenital infections (15); however, the likelihood that an infant with congenital Zika virus infection without clinical findings consistent with congenital Zika syndrome and with an initial normal hearing screen will develop hearing loss is unknown. ABR testing of infants at age 4-6 months can be considered, although the risk from sedation needs to be taken into account. Infants who passed an initial ABR and without an ABR at age 4-6 months should be referred for behavioral audiologic diagnostic testing at age 9 months, or sooner for any hearing concerns. Behavioral audiologic testing is recommended because of the potential need for sedation with ABR testing in infants.

As a critical component of patient care and to facilitate early identification of developmental delays, families should be empowered to be active participants in their child's monitoring and care. Anticipatory guidance provided to caregivers should

BOX 4. Outpatient management of infants with laboratory evidence of Zika virus infection, but without abnormalities consistent with congenital Zika syndrome

- A medical home should be established.

- Follow growth parameters, and perform developmental screening at each well child visit.

- Emphasize anticipatory guidance for families regarding developmental milestones, feeding and growth, sleep and irritability, and abnormal movements.

- Use a standardized, validated developmental screening tool at 9 months as currently recommended, or earlier for any parental or provider concerns.

- Referral to ophthalmology for comprehensive eye exam within one month of birth. Perform vision screening and assess visual regard at every well child visit, and refer to ophthalmology for any abnormal findings, or for any parental or provider concerns.

- Perform auditory brainstem response within one month of birth. Consider repeat auditory brainstem response at age 4-6 months or perform behavioral diagnostic testing at age 9 months and refer to audiology for any abnormal findings, or for any parental or provider concerns.

- Provide family and supportive services. emphasize developmental milestones, feeding and growth, sleep, irritability, and seizure recognition.

A disproportionate burden of congenital Zika virus infection might affect families with already limited access to health care. Families might face language and cultural barriers, financial barriers, and inadequate access. Rural populations might have difficulty accessing specialists. Barriers to care for all affected infants and their families should be addressed through linkage to national, state, and local health programs.

\section{Contributors}

Michael Agus, MD, Boston Children's Hospital; Donald B. Bailey, PhD, RTI International; Jim Bale, MD, University of Utah; Katherine A. Beckmann, PhD, Administration for Children and Families; Jatinder Bhatia, MD, Augusta University; Jennifer Bolden Pitre, JD, Family Voices, Inc.; Timothy J. Brei, MD, Seattle Children's Hospital; Lekisha Daniel-Robinson, MSPH, Center for Medicaid and CHIP Services, Centers for Medicare and Medicaid Services; Eric Dziuban, MD, CDC; Marcus Gaffney, MPH, CDC; Dixie D. Griffin, MD, Tift Regional Health System; Alyson B. Goodman, MD, CDC; Manda Hall, MD, Texas Department of State Health Services; R. Phillips Heine, MD, Duke University; Amy Houtrow, $\mathrm{MD}, \mathrm{PhD}$, University of Pittsburgh; Lisa Hunter, PhD, Cincinnati Children's Hospital; Susan L. Hyman, MD, University of Rochester Medical Center; Wanda K. Jones, DrPH, Office of the Assistant Secretary for Health; Bill G. Kapogiannis, MD, National Institute of Child Health and Human Development; Sharon S. Lehman, MD, Nemours Children's Health System, Sidney Kimmel Medical College of Thomas Jefferson University; Aaron Lopata, MD, Maternal and Child Health Bureau, Health Resources and Services Administration; Yvonne Maldonado, MD, Stanford University; Edward McCabe, MD, PhD, March of Dimes; Rima McLeod, MD, University of Chicago; Joan Y. Meek, MD, Florida State University College of Medicine; Michael E. Msall, MD, University of Chicago MedicineComer Children's Hospital; Lynne M. Mofenson, MD, Elizabeth Glaser Pediatric AIDS Foundation; Sitara Nayak, Parent to Parent of Georgia; Scott Needle, MD, Healthcare Network of Southwest Florida; Susan Reef, MD, CDC; Sydney Rice, MD, University of Arizona; Scott Rivkees, MD, University of Florida; Jeannie Rodriguez, $\mathrm{PhD}$, Emory University; Elizabeth Rosenblum, MD, University of California, San Diego; Pablo Sanchez, MD, Nationwide Children's Hospital; Renate Savich, MD, University of Mississippi Medical Center; Angela Scheuerle, MD, University of Texas Southwestern Medical Center; Lee Segal, MD, University of Wisconsin, Madison; Camille Smith, EdS, CDC; Parminder S. Suchdev, MD, Emory University; V. Fan Tait, MD, American Academy of Pediatrics (AAP); Edwin Trevathan, MD, Vanderbilt University School of Medicine; Camila V. Ventura, MD, Altino Ventura Foundation; Richard Whitley, MD, Children's of Alabama, University of Alabama at Birmingham; Susan Wiley, MD, Cincinnati Children's Hospital Medical Center; Fernando Ysern, MD, Puerto Rico Chapter, AAP. 


\section{Acknowledgments}

American Academy of Pediatrics (AAP); Laura Aird, MS, AAP; Giovanna Beauchamp, MD, University of Florida; Denise Boggs, CDC; Kristin Dayton, MD, University of Florida; Sean Diederich, AAP; Michelle Z. Esquivel, MPH, AAP; Jessica Franks, MPH, CDC; Margaret A. Honein, PhD, CDC; Irogue Igbinosa, MD, CDC; David W. Kimberlin, MD, University of Alabama at Birmingham; Kara Polen, MPH, CDC; Ingrid Rabe, MBChB, CDC.

${ }^{1}$ Epidemic Intelligence Service, CDC; ${ }^{2}$ Influenza Division, National Center for Immunization and Respiratory Diseases, CDC; ${ }^{3}$ Division of Viral Diseases, National Center for Immunization and Respiratory Diseases, CDC; ${ }^{4}$ Division of Environmental Hazards and Health Effects, National Center for Environmental Health, CDC; ${ }^{5}$ Division of Reproductive Health, National Center for Chronic Disease Prevention and Health Promotion, CDC; ${ }^{6}$ Division of Congenital and Developmental Disorders, National Center on Birth Defects and Developmental Disabilities, CDC; ${ }^{7}$ Office of the Director, National Center for Emerging and Zoonotic Infectious Diseases, CDC; ${ }^{8}$ Division of Vector-Borne Diseases, National Center for Emerging and Zoonotic Infectious Diseases, CDC; ${ }^{9}$ Division of Human Development and Disability, National Center on Birth Defects and Developmental Disabilities, CDC; ${ }^{10}$ Infectious Diseases Pathology Branch, Division of HighConsequence Pathogens and Pathology, National Center for Emerging and Zoonotic Infectious Diseases, CDC; ${ }^{11}$ Division of Public Health Information Dissemination, Center for Surveillance, Epidemiology, and Laboratory Services, CDC.

Corresponding authors: Kate Russell, kerussell@cdc.gov, 404-718-1178; Sara E. Oliver, seoliver@cdc.gov, 404-639-1204.

\section{References}

1. Fleming-Dutra KE, Nelson JM, Fischer M, et al. Update: interim guidelines for health care providers caring for infants and children with possible Zika virus infection-United States, February 2016. MMWR Morb Mortal Wkly Rep 2016;65:182-7. http://dx.doi.org/10.15585/mmwr.mm6507e1

2. França GV, Schuler-Faccini L, Oliveira WK, et al. Congenital Zika virus syndrome in Brazil: a case series of the first 1501 livebirths with complete investigation. Lancet 2016. Epub June 29, 2016.

3. Rasmussen SA, Jamieson DJ, Honein MA, Petersen LR. Zika virus and birth defects - reviewing the evidence for causality. N Engl J Med 2016;374:1981-7. http://dx.doi.org/10.1056/NEJMsr1604338

4. Miranda-Filho DB, Martelli CM, Ximenes RA, et al. Initial description of the presumed congenital Zika syndrome. Am J Public Health 2016;106:598-600. http://dx.doi.org/10.2105/AJPH.2016.303115

5. de Fatima Vasco Aragao M, van der Linden V, Brainer-Lima AM, et al. Clinical features and neuroimaging (CT and MRI) findings in presumed Zika virus related congenital infection and microcephaly: retrospective case series study. BMJ 2016;353:i1901. http://dx.doi.org/10.1136/bmj.i1901

6. Hazin AN, Poretti A, Turchi Martelli CM, et al.. Computed tomographic findings in microcephaly associated with Zika virus. N Engl J Med 2016;374:2193-5. http://dx.doi.org/10.1056/NEJMc1603617

7. Li C, Xu D, Ye Q, et al. Zika virus disrupts neural progenitor development and leads to microcephaly in mice. Cell Stem Cell 2016;19:120-6. http:// dx.doi.org/10.1016/j.stem.2016.04.017

8. Garcez PP, Loiola EC, Madeiro da Costa R, et al. Zika virus impairs growth in human neurospheres and brain organoids. Science 2016;352:816-8. http://dx.doi.org/10.1126/science.aaf6116

9. Tang H, Hammack C, Ogden SC, et al. Zika virus infects human cortical neural progenitors and attenuates their growth. Cell Stem Cell 2016;18:587-90. http://dx.doi.org/10.1016/j.stem.2016.02.016

10. Ventura CV, Maia M, Bravo-Filho V, Góis AL, Belfort R Jr. Zika virus in Brazil and macular atrophy in a child with microcephaly. Lancet 2016;387:228. http://dx.doi.org/10.1016/S0140-6736(16)00006-4

11. Ventura CV, Maia M, Ventura BV, et al. Ophthalmological findings in infants with microcephaly and presumable intra-uterus Zika virus infection. Arq Bras Oftalmol 2016;79:1-3. http://dx.doi.org/10.5935/0004-2749.20160002
12. Miranda HA 2nd, Costa MC, Frazão MA, Simão N, Franchischini S, Moshfeghi DM. Expanded spectrum of congenital ocular findings in microcephaly with presumed Zika infection. Ophthalmology 2016;123:1788-94. http://dx.doi.org/10.1016/j.ophtha.2016.05.001

13. Schuler-Faccini L, Ribeiro EM, Feitosa IM, et al. Possible association between Zika virus infection and microcephaly-Brazil, 2015. MMWR Morb Mortal Wkly Rep 2016;65:59-62. http://dx.doi.org/10.15585/mmwr.mm6503e2

14. Corona-Rivera JR, Corona-Rivera E, Romero-Velarde E, HernándezRocha J, Bobadilla-Morales L, Corona-Rivera A. Report and review of the fetal brain disruption sequence. Eur J Pediatr 2001;160:664-7. http://dx.doi.org/10.1007/s004310100813

15. Fowler KB, Stagno S, Pass RF, Britt WJ, Boll TJ, Alford CA. The outcome of congenital cytomegalovirus infection in relation to maternal antibody status. N Engl J Med 1992;326:663-7. http://dx.doi.org/10.1056/ NEJM199203053261003

16. Sever JL, South MA, Shaver KA. Delayed manifestations of congenital rubella. Rev Infect Dis 1985;7(Suppl 1):S164-9. http://dx.doi. org/10.1093/clinids/7.Supplement_1.S164

17. Fowler KB, McCollister FP, Dahle AJ, Boppana S, Britt WJ, Pass RF. Progressive and fluctuating sensorineural hearing loss in children with asymptomatic congenital cytomegalovirus infection. J Pediatr 1997;130:624-30. http://dx.doi.org/10.1016/S0022-3476(97)70248-8

18. Cannon MJ, Hyde TB, Schmid DS. Review of cytomegalovirus shedding in bodily fluids and relevance to congenital cytomegalovirus infection. Rev Med Virol 2011;21:240-55. http://dx.doi.org/10.1002/rmv.695

19. Rawls WE, Phillips A, Melnick JL, Desmond MM. Persistent virus infection in congenital rubella. Arch Ophthalmol 1967;77:430-3. http:// dx.doi.org/10.1001/archopht.1967.00980020432003

20. Rabe IB, Staples JE, Villanueva J, et al. Interim guidance for interpretation of Zika virus antibody test results. MMWR Morb Mortal Wkly Rep 2016;65:543-6. http://dx.doi.org/10.15585/mmwr.mm6521e1

21. Masuzaki H, Miura K, Miura S, et al. Labor increases maternal DNA contamination in cord blood. Clin Chem 2004;50:1709-11. http:// dx.doi.org/10.1373/clinchem.2004.036517

22. Oduyebo T, Igbinosa I, Petersen EE, et al. Update: interim guidance for health care providers caring for pregnant women with possible Zika virus exposure-United States, July 2016. MMWR Morb Mortal Wkly Rep 2016;65:739-44. http://dx.doi.org/10.15585/mmwr.mm6529e1

23. Besnard M, Lastere S, Teissier A, Cao-Lormeau V, Musso D. Evidence of perinatal transmission of Zika virus, French Polynesia, December 2013 and February 2014. Euro Surveill 2014;19:20751. http://dx.doi. org/10.2807/1560-7917.ES2014.19.13.20751

24. Committee on Practice and Ambulatory Medicine and Bright Futures Periodicity Schedule Workgroup. 2016 recommendations for preventive pediatric health care. Pediatrics 2016;137:1-3.

25. Olson CK, Iwamoto M, Perkins KM, et al. Preventing transmission of Zika virus in labor and delivery settings through implementation of standard precautions-United States, 2016. MMWR Morb Mortal Wkly Rep 2016;65:290-2. http://dx.doi.org/10.15585/mmwr.mm6511e3

26. Dupont-Rouzeyrol M, Biron A, O'Connor O, Huguon E, Descloux E. Infectious Zika viral particles in breastmilk. Lancet 2016;387:1051. http://dx.doi.org/10.1016/S0140-6736(16)00624-3

27. Kuo DZ, Houtrow AJ, Arango P, Kuhlthau KA, Simmons JM, Neff JM. Family-centered care: current applications and future directions in pediatric health care. Matern Child Health J 2012;16:297-305. http:// dx.doi.org/10.1007/s10995-011-0751-7

28. Birkebaek NH, Patel L, Wright NB, et al. Endocrine status in patients with optic nerve hypoplasia: relationship to midline central nervous system abnormalities and appearance of the hypothalamic-pituitary axis on magnetic resonance imaging. J Clin Endocrinol Metab 2003;88:5281-6. http://dx.doi.org/10.1210/jc.2003-030527

29. American Academy of Pediatrics. Healthy children. Elk Grove Village, IL: American Academy of Pediatrics; 2016. https://www.healthychildren.org

30. Marcin JP, Shaikh U, Steinhorn RH. Addressing health disparities in rural communities using telehealth. Pediatr Res 2016;79:169-76. http:// dx.doi.org/10.1038/pr.2015.192 